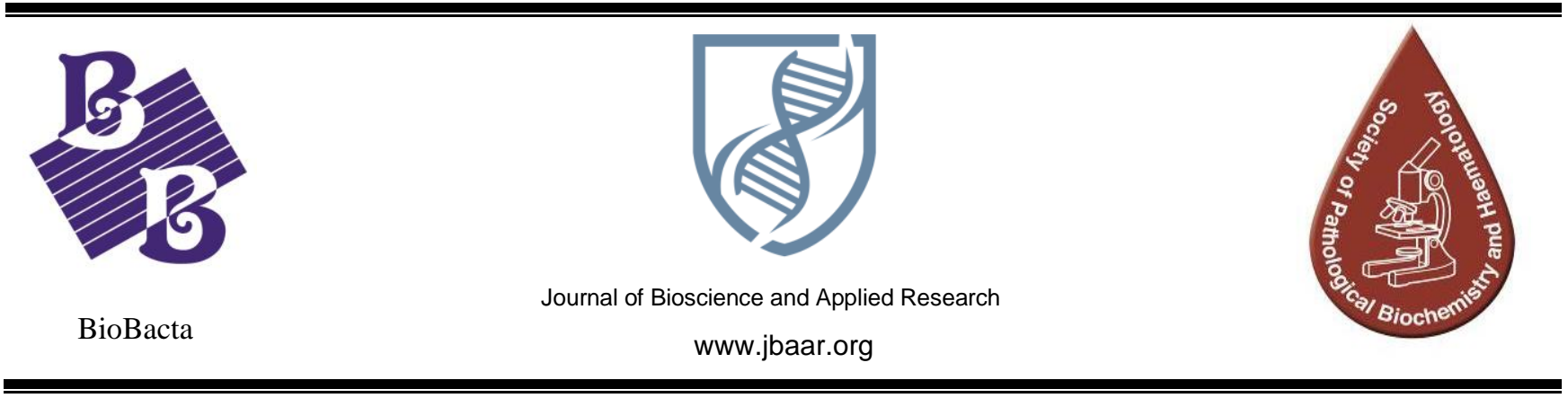

\title{
A Correlational Approach on the Link between Emotional Intelligence and Stress Level of Nursing Students
}

\author{
Jordan H. Llego, RN, Ph.D., FRIHC, FRIN, FRIRes, Jennie L. Corpus, RN, FRIN \\ College of Nursing and Midwifery, University of Luzon \\ Perez, Boulevard, Dagupan City 2428 Philippines \\ (Email: llegojordan@gmail.com) \\ Received date: January 12, 2018. Accepted: February 14, 2019 \\ DOI: $10.21608 /$ JBAAR.2019.105991
}

\begin{abstract}
The aim of this research study is to assess the level of emotional intelligence, the stress level, and the link between the two variables. This study will use descriptive-correlational design through the use of a questionnaire; total enumeration was employed with 32 respondents. The data collected were analyzed using SPSS version 22, and mean, and Pearson-r was utilized. The mean score reveals a score of 112.29, which means that the respondents have average emotional intelligence. The mean reveals a score of 20.59, which means that the respondents are experiencing a moderate level of stress. The Pearson-r yielded a score of $(r=-$ $0.32, \mathrm{n}=34, \mathrm{p}=0.70$ ) which means that there is no significant relationship between the two variables. Conclusions include: the respondents can assess others' emotion, moreover their emotion with an acceptable level of emotional control, and thus they can interact satisfactorily with other people, and positively use their emotion with a positive outlook in life; the respondents are adapting to the stress they are experiencing, and the emotional intelligence of the respondents does not have a link with their stress level.
\end{abstract}

\section{Keywords: Emotional Intelligence, Nursing Education, Stress, Quantitative Analysis}

\section{Introduction}

According to the Institute for Health and Human Potential (2018), emotional intelligence is the ability to recognize, understand and manage their own emotions and the ability to identify, understand and influence the emotions of others; this means being aware that emotions can drive our behavior and impact people positively or negatively, and learn how to manage our and others' emotions especially when we are under pressure. Furthermore, Durlofsky (2015), claims that emotional intelligence can greatly influence the success of a person because it affects one's choices by creating options that may not have otherwise considered to be a possibility.

On the other hand, stress has many effects on a person it can affect the nervous system, musculoskeletal system, respiratory system, cardiovascular system, endocrine system, and the gastrointestinal system. Furthermore, stress is linked to depression, anxiety, heart attacks, stroke, hypertension, immune system disturbances that increase susceptibility to infections (American Institute of Stress, 2017), this effect of stress could affect any individual. According to Chua (2011), no one alive is exempt from stress. Moreover, stress could motivate other people to perform their best under pressure, but some people buckle down and become useless when faced with stress.

Stress is also one of the toughest things a student can face. Students complain of being "too stress" with academic works that they have to submit on or before a deadline (Ho, 2016). Moreover, Cuerpo (2017), stress is a significant factor in how a child performs academically. Research done in 2000 on learning theories states that stress can hasten learning ability, but a high level of it can cause physical and mental 
health problems and the academic performance of a student is put to risk. These problems according to both authors are related to the time and deadline the students are facing.

Healthcare workers in a report are $69 \%$ stress, and $12 \%$ are highly stressed. "Stress is part of the environment in many healthcare settings, but high levels sustained over a long period can be a major detriment to employee health and ultimately stand in their way of providing quality care to patients," says Jason Lovelace, president of CareerBuilder Healthcare. Furthermore, 55\% of healthcare workers reported that they have increased workload over the past years (Ricker, 2014).

In the medical field, de Castro, Cabrera, Gee, Fujishiro, and Tagalog (2009), conducted a study to examine the occupational health and safety issues among Filipino Nurses; the result revealed that topranking concerns were stress and overwork. Another study was conducted by Salvacion (2015), were in the researcher looked at the stress profile of Dentistry students at the University of the Philippines. Results of the study showed that the majority of the students manifested high stress, and academic works and clinical requirements were the top external sources of stress while frustration and overload were the primary internal causes of stress.

Meanwhile, according to Goleman (2012), emotional intelligence should help a person to handle stress better. According to him, there four factors of emotional intelligence which are self-awareness, selfmanagement, and empathy. Self-awareness can help a person notice when he is becoming stressed, which in turn makes him better to calm down before a reaction builds to an unmanageable level. Empathy and social skill should allow a person to be more effective in how he expresses himself-including knowing how and when to be candid. Moreover, according to Crockett (2018), having emotional intelligence opens gateways to powerful learning, and you can help your students find it. "Learners become clear-headed, confident, and eager to explore the unknown. They work better together, share stronger communications, and overcome obstacles to discovery with ease." Moreover, according to the author, the emotional intelligence could also enhance the stress management of a person.

With all these in mind, the researchers want to assess the level of emotional intelligence, the stress level, and the link between the two variables. The result of this research work will also serve as a baseline data of the university on the level of emotional intelligence and stress level of the respondents and the relationship between those variables.

This study will answer the following questions: 1 . What is the level of emotional intelligence of the respondents? 2. What is the stress level of the respondents? 3. Is there a significant relationship between the emotional intelligence and stress level of the respondents? This study was guided by the hypothesis that there is no significant relationship between the level of emotional intelligence and stress level.

\section{Materials and Methods}

\section{Research Design}

This study will use descriptive-correlational design. According to Polit and Beck, (2017), this design aims to examine a sample at one specific point in time without making any inferences or causation. The study will give meaning to the variables being assessed, and a correlational study aims to examine the relationship between two variables. The study describes the emotional intelligence and the stress level of the respondents, and this study looks at the relationship between emotional intelligence and stress level without inferring causation. Thus, these research designs apply to this study.

\section{Population and Sampling}

The locale of the study is a University situated at Dagupan City, Pangasinan. Specifically, the research focuses on nursing students. There are 32 nursing students at the university. The total enumeration was applied in this study to represent the population adequately (Laerd Dissertaion, 2012).

\section{Respondents of the Study}

The respondents of this study are the nursing students in a university in Dagupan, City, regardless of age and sex, the respondents will assess their stress level. The freshmen nursing students were excluded from this study because they are in their first year and assume that they are experiencing less stress than the higher years.

\section{Data Gathering Instrument}


The primary data gathering tool for the study is a questionnaire. The questionnaire is composed of two parts. Part I (one) was adopted from Llego (2016), which was based on The Schutte Self Report Emotional Intelligence Test (SSEIT), the questionnaire was organized as, "strongly disagree (1)," "disagree (2)," "neither disagree nor agree (3)," "agree (4)," "strongly agree (5)," this is to measure the EI level of the respondents.

Part II (two) assess was adopted from the Perceived Stress Scale; this was used because it is already tested to measure the stress level of an individual, and it is widely used and already available. Part II is composed of 10 items, and is answerable by the following scale " 0 - never," "1almost never," "2-sometimes," "3- fairly often," "4very often." Moreover, items 4, 5, 7, and eight will be treated with reverse scoring.

\section{Ethical Consideration}

Before the actual data collection, the researchers get the approval of the research coordinator for the BSN program. There is also a letter of consent that is attached to the questionnaire that is answered by the respondents, indicating the purpose of the study, the time needed to finish answering the questionnaire. In the consent form of the students, it is also stated that they are allowing access to their NCM grades but the researchers. Further, the respondents have the right to refuse not to participate in the study without any coercion.

All data will be treated with the highest respect, confidentiality, and anonymity.

\section{Data Gathering Procedure}

After securing all the approval needed by the researchers, they administered the questionnaire; they stayed with the respondents during the data gathering so that if there are any questions, they are available for clarifications.

Data collection and retrieval was on June 25-26, 2018.

\section{Tools for Data Analysis}

The collected data in this study were analyzed using the Statistical Package for Social Sciences (SPSS) version 22.

To answer sub-problems number one and two, the mean was utilized because these data are continuous data.

To answer sub-problem number three, Pearson-r was utilized because both data are considered continuous data.

\section{Results}

\section{Table 1}

\section{The Level of Emotional Intelligence of the Respondents}

\begin{tabular}{|l|l|}
\hline Level & Interpretation \\
\hline 112.29 & Average \\
\hline
\end{tabular}

Table 1: reveals the level of emotional intelligence of the respondents; the mean score reveals a score of 112.29, which means that the respondents have average emotional intelligence.

\section{Table 2}

The Level of Stress of the Respondents

\begin{tabular}{|l|l|}
\hline Level & Interpretation \\
\hline 20.59 & Moderate Stress \\
\hline
\end{tabular}

Table2: delineates the stress level of the respondents it can be gleaned that mean reveals a score of 20.59, which means that the respondents are experiencing a moderate level of stress.

Table 3

\section{The Relationship between Emotional Intelligence} and Stress Level of the Respondents

\begin{tabular}{|l|l|l|}
\hline r-value & $\mathbf{p}$-value & Interpretation \\
\hline-0.32 & 0.70 & No significant relationship \\
\hline
\end{tabular}

Table 3: shows the significant relationship between the emotional intelligence and stress levels of the respondents. It can be seen that the $(r=-0.32$, $\mathrm{n}=34, \mathrm{p}=0.70$ ) which means that there is no significant relationship between the two variables. Hence, emotional intelligence has no vital link to the stress level of the respondents. 


\section{Discussion}

The finding shows that the respondents are functioning efficiently, handling situations, and meeting environmental demands (Campbell, n.d.).

According to Doctor Robertson a neuroscientist as cited in Rodionova (2016), stress can push us to perform better, "There's a sweet spot in the middle where if you have just the right amount, the Goldilocks zone of noradrenaline, that acts like the best brain-tuner."

It can be seen that there is no significant relationship between emotional intelligence and stress level of the respondents; this means that there is no link between the two variables. This finding is supported by Yamani, et al., (2014), that states that there is no significant relationship between emotional intelligence and stress among the faculty of medicine at Isfahan University. This is also supported by the finding of Miri, et al., (2013), wherein they found out that there was no significant correlation between emotional intelligence and educational stress in medical science students.

Salvacion (2004) studied the stress profile of students in the College of Dentistry of the University of the Philippines, Manila, and found out that stress has a negative relationship to the academic performance of the students. Siraj, et al., (2014), discovered that medical students have a higher stress level, and stress level has a positive relationship with their academic performance; which means that the higher stress they are facing, the better their academic performance is. While in the field of nursing Goff (2011), found out that the stress level of nursing students has no significant relationship between their academic performance.

In light of the findings of the study, the researchers conclude the following: the respondents can assess others' emotions. Moreover, their emotional control is within an acceptable level, and thus they can interact satisfactorily with other people, and positively use their emotion with a positive outlook in life; the respondents are adapting to the stress they are experiencing, and the emotional intelligence of the respondents does not have a link with their stress level.

In light of the findings and conclusions of this study, the researcher recommends that the faculty members of the College of Nursing of the University should incorporate activities that could enhance their emotional intelligence. The researchers also encourage the Administrators of the College of Nursing to conduct seminars and training about the importance of emotional intelligence and the enhancement of it. The researchers also encourage the faculty members of the College of Nursing to have a consultation with their students regarding their stress level, so that the students can verbalize their feelings. Also, the researchers also recommend that there will be a stress-relief program for the students so that, they will feel more at ease when doing their assigned tasks.

\section{References}

Campbell. (n.d.). Emotional Intelligence: Why does it matter? Retrieved August 2018 from http://populationleaders.washington.edu/internal/EmotionalIntelligenc e.pdf

Crockett. (2018). This is How Emotional Intelligence Can Help Your Students Learn. Retrieved August 2018 from https://globaldigitalcitizen.org/emotionalintelligence-infographic

Cuerpo, J. (2007). Too much work, too little time. SunStar Philippines. Retrieved June 2018 from https://www.sunstar.com.ph/article/402552/

de Castro, de Castro, Cabrera, Gee, Fujishiro, and Tagalog (2009). Occupational Health and Safety Issues Among Nurses in the Philippines. Retrieved from

https://www.ncbi.nlm.nih.gov/pubmed/19438081

Durlofsky. (2015). The Benefits of Emotional Intelligence. Retrieved August 2018 from https://psychcentral.com/blog/the-benefits-ofemotional-intelligence/

Goff, AM. (2011). Stressors, academic performance, and learned resourcefulness in baccalaureate nursing students. International Journal of Nursing Education Scholarship, 8(1).Retrieved June 2018 from https://doi.org/10.2202/1548-923X.2114

Goleman. (2012). Emotional Intelligence and Stress. Retrieved August 2018 from http://www.danielgoleman.info/emotionalintelligence-and-stress/ 
Ho, G. (2016). 5 Stress triggers college students can relate to. ABS-CBN News.com. Retrieved June 2018 from http://news.abscbn.com/advertorial/life/11/18/16/5-stress-triggerscollege-students-can-relate-to

Institute for Health and Human Potential. (2018). What is Emotional Intelligence? Retrieved August 2018 from https://www.ihhp.com/meaning-ofemotional-intelligence

Laerd Dissertation (2012). Total Population Sampling. Laerd Dissertation. Retrieved June 2018 from http://dissertation.laerd.com/total-populationsampling.php

Miri, Kirnani, Khosbakhht, Moodi. (2013). The relationship between emotional intelligence and academic stress in students of medical sciences. Retrieved August 2018 from https://www.researchgate.net/publication/257251281 _The_relationship_between_emotional_intelligence_ and_academic_stress_in_students_of_medical_scienc es

Polit, D. and Beck C. (2017). Essentials of Nursing Research Ninth Edition. Lippincott Williams \& Wilkins: USA

Ricker, S. (2014). Stress is part of the job of healthcare workers. CareerBuilder. Retrieved June 2018 from https://www.careerbuilder.com/advice/stress-is-partof-the-job-for-health-care-workers

Rodionova. (2016). Why Moderate Amount of Stress is Good for You. Retrieved August 2018 from https://ianrobertson.org/moderate-amount-stressgood-according-cognitive-neuroscientist/

Salvacion. (2015). Stress Profile among Students of the UP Manila College of Dentistry. Retrieved June 2018 from http://pjhrd.upm.edu.ph/index.php/main/article/view/ 50

Salvacion. (2004). Stress Profile of Students of the University of the Philippines College of Dentistry. Unpublished Thesis. University of the Philippines, Manila.
Yamani, Shahabi, and Haghani. (2014). The relationship between emotional intelligence and job stress in the faculty of medicine in Isfahan University of Medical Sciences. Retrieved August 2018 from https://www.ncbi.nlm.nih.gov/pmc/articles/PMC423 5538/ 